\title{
Desenvolvimento socioeconômico de Santana do Livramento: uma análise pelo IFDM
}

\author{
Amanda da Maia Alves \\ Debora Nayar Hoff
}

\begin{abstract}
Resumo
O presente artigo tem por objetivo analisar o desenvolvimento socioeconômico do município de Santana do Livramento entre os anos de 2005 e 2016, buscando entender as mudanças que ocorreram neste período. Para este fim, foram usados dados do índice IFDM, desdobrado em Emprego e Renda, Saúde e Educação. Complementarmente, foram utilizados dados secundários de informações do município e análises qualitativas a partir de entrevistas com os gestores de cada área. De acordo com os resultados, é possível afirmar que 2016 foi o ano de maior desenvolvimento socioeconômico do município, tendo o IFDM alcançado o valor de 0,7597 (considerado como de 'desenvolvimento moderado'). Pode-se observar que a Saúde foi o indicador que mais contribuiu para elevar o IFDM do município, apresentando melhoras no seu índice, sobretudo, nos períodos de 2008-2010 e 2014-2016, quando alcançou a condição de 'desenvolvimento alto'. Outro indicador que apresentou melhora no período foi a Educação, que terminou o período analisado como sendo de 'desenvolvimento moderado'. Porém, a área de Emprego e Renda demonstrou ser a mais carente, em alguns anos estacionando no patamar de 'desenvolvimento regular'.
\end{abstract}

Palavras-chave | Desenvolvimento socioeconômico local; IFDM; indicadores; Santana do Livramento.

Classificação JEL | I31 I32 O18

\section{Santana do Livramento's socio-economic development: an analysis using IFDM}

\begin{abstract}
The purpose of this article is to analyze the socioeconomic development of the municipality of Santana do Livramento through 2005 to 2016, trying to understand the changes that occurred in this period. To analyze the socioeconomic development, the IFDM index was used, broken down into Employment and Income, Health and Education. Complementarily, secondary information data of the municipality and qualitative analyzes were used through interviews with
\end{abstract}


the managers of each area. According to the results obtained it is possible to affirm that the year of 2016 was the year with the greatest socioeconomic development, with an IFDM of 0.7597 being considered as a moderate development in the municipality. It was possible to observe that Health was the indicator that contributed the most to raise the IFDM of the municipality, showing improvements in its index, mainly in the periods of 2008 to 2010 and 2014 to 2016 in which it reached a high development, according to the standards of for the IFDM. Another indicator that showed an improvement in the period was Education, which ended the period analyzed as being of moderate development. However, the area of Employment and Income was the most deprived, being in some years at the level of regular development.

Keywords I IFDM; indicators; local socio-economic development; Santana do Livramento.

JEL Classification | I31 I32 O18

\section{Desarrollo socioeconómico de Santana do Livramento: un análisis por el IFDM}

\section{Resumen}

El presente artículo tiene como objetivo analizar el desarrollo socioeconómico del municipio de Santana do Livramento entre 2005 y 2016, buscando comprender los cambios que se produjeron en este período. Para ese fin, se utilizaron datos del índice IFDM, desglosado en Empleo e Ingresos, Salud y Educación. Complementariamente, se utilizaron datos secundarios de información del municipio y análisis cualitativos a partir de entrevistas con los gerentes de cada área. De acuerdo con los resultados, es posible afirmar que el 2016 fue el año de mayor desarrollo socioeconómico del municipio, con un IFDM alcanzado de 0.7597 (considerado como "desarrollo moderado"). Se pudo observar que la salud fue el indicador que más contribuyó para elevar el IFDM del municipio, mostrando mejoras en su índice, principalmente, en los períodos de 2008-2010 y 2014-2016, en los que alcanzó la condición de "desarrollo alto". Otro indicador que mostró una mejora en el período fue Educación, que terminó el período analizado como "desarrollo moderado". Sin embargo, el área de Empleo e Ingresos fue la más desfavorecida, en algunos años obteniendo un nivel de "desarrollo regular".

Palabras clave | Desarrollo socioeconómico local; IFDM; indicadores; Santana do Livramento.

Clasificación JEL | I31 I32 O18

\section{Introdução}

Discussões sobre desenvolvimento, dentro da ciência econômica, vêm sendo feitas desde as teorias clássicas, mesmo que naquele período a questão central fosse o crescimento das economias e a acumulação de capital. Num conceito tradicional e contemporâneo, pode-se dizer que o desenvolvimento econômico é um processo que engloba acumulação de capital com incorporação de progresso técnico, que 
ajuda a elevar a produtividade ou a renda do trabalhador, tendo por consequência o bem-estar da sociedade (BRESSER-PEREIRA, 2006).

O entendimento do processo de desenvolvimento evolui ao longo do tempo, extrapolando a lógica exclusiva do aumento de produção e riqueza para incluir a forma como estes refletem-se em bem-estar da sociedade. Esta evolução afetará, entre outras coisas, a construção da noção de desenvolvimento socioeconômico, implicando também na reformulação das formas de medir-se o processo. Se inicialmente o conceito de desenvolvimento foi associado apenas ao crescimento econômico e podia ser medido pelo Produto Interno Bruto (PIB), numa concepção ampliada, tornou-se necessário adicionar novas variáveis aos indicadores de desenvolvimento. Estas variáveis abordavam questões na área da educação, habitação e saúde para melhor definir o desenvolvimento socioeconômico (SIEDENBERG, 2011). A aplicação destes indicadores para o estudo das regiões possibilita um novo conjunto de entendimentos acerca das realidades de desenvolvimento.

Neste contexto, observando-se a evolução do Brasil, pode-se dizer que este passou por um processo de crescimento econômico, com desigualdade social, no período de 1950 a 1980. De 1980 a 1990 passou por um período de estagnação econômica e crise, o que contribuiu para ampliar as desigualdades sociais. Paralelamente, passou por importantes fatos históricos, como o restabelecimento da democracia e a promulgação da Constituição Federal de 1988, os quais pretendiam trazer melhorias para a sociedade, pois sinalizavam o acesso a direitos sociais como segurança, trabalho, saúde, educação, lazer, previdência social, assistência aos desamparados e proteção à maternidade e à infância (OLIVEIRA, 2017; SILVA, 2018; LAMPREIA, 1995).

Esta realidade evidencia-se nos primeiros anos do século XXI, pois medidas de inclusão social, políticas públicas e econômicas, investimento e infraestrutura adotados pelo governo, bem como o crescimento econômico observado, fizeram com que o Brasil atingisse níveis significativos de desenvolvimento (BRASIL, 2013).

Se analisado o Rio Grande do Sul (RS) dentro deste contexto, pode-se também afirmar que o estado vem numa crescente melhora no seu desenvolvimento socioeconômico, com alguns indicadores superiores aos nacionais (PNUD, 2018; IPEA, 2017; IPEA, 2018). No entanto, o estado do Rio Grande do Sul demonstra diferenças regionais importantes. A metade norte do estado conseguiu alcançar um nível de desenvolvimento via da industrialização, enquanto a metade sul manteve as características históricas de concentração fundiária e ênfase na produção agropecuária, com baixa industrialização (AREND; CARIO, 2010).

O município de Santana do Livramento, objeto deste estudo, situa-se na metade sul do Rio Grande do Sul, fazendo limite com a cidade de Rivera, no Uruguai. Já foi um dos grandes centros econômicos do Rio Grande do Sul e teve seu auge econômico nas primeiras décadas do século XX. $\mathrm{Na}$ época, com industrialização 
presente via frigoríficos, lanifício e cervejaria, chegou a ser o terceiro município mais industrializado do RS (FAVERO; DUARTE, 2017; SHÄFFER, 1993; CAGGIANI, 1983, 1991). Porém, em 1970 a atividade industrial de Santana do Livramento começou a declinar, com a crise se intensificando nas décadas seguintes (MONTEBLANCO, 2013; MELO, 2013; SHÄFFER, 1993). Desde então, o município passou a depender do comércio de fronteira, pecuária e tipos de culturas extensivas como elementos dinâmicos de sua economia (FAVERO; DUARTE, 2017).

Para o ano de 2017 (dado mais recente disponível na fonte de informação), 11,83\% do PIB tinha origem no setor agropecuário, 33,02\% no setor industrial e 55,15\% no setor de serviços (IBGE, 2020). Nas atividades primárias têm destaque a produção pecuária, acompanhada recentemente da fruticultura. O setor terciário vem com um crescente desenvolvimento, impulsionado em grande parte pelo turismo de comércio possibilitado pelos freeshops uruguaios. Em 2002 contava com uma participação de $58 \%$ da população economicamente ativa, chegando a 63,54\% desta no ano de 2010 (SÁNCHEZ, 2002). No início do século XXI, o crescimento econômico gerado por estes setores mostrava-se ainda insuficiente, fazendo com que a região fosse classificada como de economia estagnada (MIN, 2011).

As ações do governo federal, algumas originadas do Plano Nacional de Desenvolvimento Regional (PNDR), e ações do governo estadual, têm objetivado, ao longo dos últimos anos, melhorar a dinâmica econômica dos municípios de economia estagnada ou deprimida. Reflexo destas ações são a instalação da Unipampa, o desenvolvimento do parque eólico, o aumento de secretarias e autarquias públicas localizadas no município e o aumento do contingente de servidores públicos federais. Além disso, a iniciativa privada regional vem também contribuindo para a construção alternativas para a diversificação da economia. Entre estas pode-se destacar a evolução da vitivinicultura; a emergência da olivicultura; a busca por diferenciação da produção de carne em função de características do território; a emergência da organização de uma cadeia leiteira, inclusive com a produção local de laticínios; e a busca por desenvolver-se o turismo receptivo. Todas estas ações tendem a modificar a realidade recente do desenvolvimento regional.

Dentro desse contexto, o objetivo geral deste artigo é analisar o desenvolvimento socioeconômico no município entre o período de 2005 a 2016, considerando-se o Índice Firjan de Desenvolvimento Municipal (IFDM), complementado por outros indicadores econômicos e sociais. O trabalho está organizado em mais quatro seções além desta primeira introdutória. A segunda seção trata da referência bibliográfica sobre o desenvolvimento até chegar ao desenvolvimento socioeconômico e evolução dos indicadores. A terceira seção discorre sobre a metodologia aplicada neste estudo. A quarta seção apresenta os resultados obtidos e respectivas análises. Finalmente a quinta seção traz as considerações finais. 


\section{Desenvolvimento socioeconômico: noção e indicadores}

De acordo com Souza (1994) e Santos et al. (2012), a preocupação com desenvolvimento ganha importância a partir das discussões propostas pelos clássicos da economia: Adam Smith, David Ricardo, Thomaz Malthus e Karl Marx. $\mathrm{Na}$ visão deles, o conceito de desenvolvimento está focado na acumulação de riqueza junto com a expectativa de um bem-estar maior no futuro. $\mathrm{O}$ desenvolvimento, enquanto crescimento econômico e acumulação de capital, é o condutor do avanço de uma sociedade (SANTOS et al., 2012).

Com a emergência das teorias neoclássicas, essa ideia se firma. Para esta corrente, o desenvolvimento em determinado tempo e espaço trará, à toda sociedade, o mesmo nível de progresso social, material e cultural dos países capitalistas. Porém, ao longo do tempo, o nível do progresso não se tornou igual para todos, ocorrendo um distanciamento entre países pobres e ricos (SANTOS et al., 2012).

$\mathrm{Na}$ década de 1940 o desenvolvimento ganhou um arcabouço teórico e metodológico para ser descrito como uma sociedade que detém riqueza, por meio de acúmulo de capital (SANTOS et al., 2012). O processo de industrialização era visto como fator decisivo para que houvesse o desenvolvimento, sendo até mesmo tratado como sinônimo ou instrumento principal do fenômeno na época (MALUF, 2000).

O desenvolvimento nos anos 1960 girava mais em torno do crescimento econômico, sem muitas variáveis a serem analisadas. Porém, com o passar dos anos, começaram a surgir novos conceitos e caminhos para o desenvolvimento, como o social, o humano e o sustentável. Neste contexto, o crescimento econômico passou a ser uma variável de um processo maior (CARDOSO, 1995). A dimensão social passou a ser considerada como um dos componentes essenciais do processo de desenvolvimento devido à relevância para a evolução das atividades do sistema econômico. Entende-se que se não houver investimento no ser humano, as áreas produtivas e de infraestrutura não funcionarão de forma adequada (DOWBOR, 2001).

É neste âmbito que surgem as ideias e conceitos trabalhados por Amartya Sen, ganhando espaço na discussão do desenvolvimento, agora como socioeconômico (NIEDERLE; RADOMSKY, 2018). Sen (2000), quando defende a ideia de desenvolvimento como liberdade, busca destacar o papel das diversas liberdades na constituição do desenvolvimento do indivíduo e das regiões. Para ele, só com liberdade política, oportunidade social, facilidades econômicas, segurança protetora e garantias de transparência é que se constituirá uma sociedade realmente desenvolvida (NIEDERLE; RADOMSKY, 2018).

Dentro desse contexto de desenvolvimento socioeconômico, a Cúpula Mundial realizou seu primeiro grande encontro internacional, a Conferência de Copenhague, 
em março de 1995, para tratar da importância do desenvolvimento social. A convite das Nações Unidas, os chefes de estado e governo se encontraram para discutir e entender a importância do bem-estar humano para o desenvolvimento dos países, sinalizando objetivos prioritários para o longo prazo (ALVES, 1997). Nesta Conferência ficou estabelecido que "o Desenvolvimento Social é, portanto, entendido como o processo de garantia de condições sociais mínimas, bem como de promoção da dimensão social do bem-estar..." (AMARO, 2003, p. 18). Para além disso, "o desenvolvimento deve ser encarado como um processo complexo de mudanças e transformações de ordem econômica, política e, principalmente, humana e social" (OLIVEIRA, 2002, p. 40).

O grande anseio presente é que a qualidade de vida alcance todo o espectro das camadas sociais, de forma a criar um novo cenário social de equidade entre a população (OLIVEIRA, 2002). Para tanto, as políticas públicas ganham importância, uma vez que o alcance de um patamar mais alto de qualidade de vida passa por investimentos contínuos em infraestrutura urbana, saúde e educação (KLIKSBERG, 1998). A partir deste novo pensamento, busca-se construir indicadores capazes de identificar a riqueza da nação, mas que também sejam capazes de identificar os efeitos desta riqueza sobre a realidade socioeconômica da população (NIEDERLE; RADOMSKY, 2018).

Vários esforços foram estabelecidos neste sentido, sendo o mais conhecido aquele que resultou no Índice de Desenvolvimento Humano (IDH), o qual avalia a qualidade de vida e o desenvolvimento econômico de uma população, considerando indicadores de educação (alfabetização e taxa de matrícula), longevidade (esperança de vida ao nascer) e renda (PIB per capita) (resultado do trabalho de Amartya Sen). $\mathrm{Na}$ esteira deste, outros indicadores foram estabelecidos no mesmo sentido, como o escolhido para dar suporte a esta pesquisa, o Índice Firjan de Desenvolvimento Municipal (IFDM).

O IFDM foi elaborado pela Federação das Indústrias do Estado do Rio de Janeiro (Firjan), para observar o desenvolvimento dos municípios brasileiros. Foi inspirado no Índice de Desenvolvimento Humano (IDH) e avalia emprego e renda, saúde e educação. Seu cálculo é feito a partir da média aritmética dos seus três componentes e considera dados oficiais que os municípios são obrigados a declarar e que são disponibilizados por eles e pelos ministérios do Trabalho, da Educação e da Saúde (FIRJAN, 2017). O índice é calculado para todos os municípios do país e apresenta uma boa periodicidade, o que motivou sua escolha para este estudo. Os indicadores que compõe o IFDM podem ser observados no Quadro 1. 


\section{Quadro 1 - Índice Firjan de Desenvolvimento Municipal (IFDM)*}

\begin{tabular}{|c|c|c|}
\hline EMPREGO E RENDA & EDUCAÇÃO & SAÚDE \\
\hline Geração de emprego formal & $\begin{array}{l}\text { Matrículas na educação } \\
\text { infantil }\end{array}$ & $\begin{array}{l}\text { Número de consultas pré- } \\
\text { natal }\end{array}$ \\
\hline $\begin{array}{l}\text { Absorção da mão de obra } \\
\text { local }\end{array}$ & $\begin{array}{l}\text { Abandono no ensino } \\
\text { fundamental }\end{array}$ & $\begin{array}{l}\text { Óbitos por causas mal } \\
\text { definidas }\end{array}$ \\
\hline Geração de Renda formal & $\begin{array}{c}\text { Distorção idade-série no } \\
\text { ensino fundamental }\end{array}$ & $\begin{array}{l}\text { Óbitos infantis por causas } \\
\text { evitáveis }\end{array}$ \\
\hline $\begin{array}{l}\text { Salários médios do emprego } \\
\text { formal }\end{array}$ & $\begin{array}{l}\text { Docente com ensino superior } \\
\text { no ensino fundamental }\end{array}$ & $\begin{array}{l}\text { Internação sensível à atenção } \\
\text { básica (ISAB) }\end{array}$ \\
\hline \multirow[t]{2}{*}{ Desigualdade } & $\begin{array}{l}\text { Média de horas aula diárias } \\
\text { no ensino fundamental }\end{array}$ & \\
\hline & $\begin{array}{l}\text { Resultado do Índice de } \\
\text { Desenvolvimento da } \\
\text { Educação Básica (IDEB) no } \\
\text { ensino fundamental }\end{array}$ & \\
\hline
\end{tabular}

Fonte: Firjan, 2019.

*A coleta dos dados remete ao Ministério do Trabalho e Emprego; Ministério da Educação e Ministério da Saúde.

A leitura dos resultados do IFDM varia de 0 a 1 e quanto mais próximo de 1 , maior é o desenvolvimento do local estudado. A escala utilizada para análise é a seguinte: entre 0,0 e $0,4=$ desenvolvimento baixo; entre 0,4 e $0,6=$ desenvolvimento regular; entre 0,6 e $0,8=$ desenvolvimento moderado; entre 0,8 e $1,0=$ desenvolvimento alto. Esta escala apresenta problemas estatísticos, por não indicar se os números limites estão inclusos ou não em cada subgrupo definido, mas sendo a orientação metodológica da Firjan, ela será usada como proposta.

\section{Metodologia}

A contextualização histórica do município, apresentada na introdução, contou com pesquisa bibliográfica e documental. Para descrever a situação atual do desenvolvimento socioeconômico foram utilizados dados do Índice Firjan de Desenvolvimento Municipal (IFDM), atualizado até o ano de 2016 (último ano disponível para o índice quando da elaboração do estudo), juntamente com os seguintes dados secundários: PIB e renda per capita, número de habitantes, faixa etária da população, população economicamente ativa, pessoal ocupado e ocupado assalariado, remuneração média, número de empresas atuantes no município, Índice de Gini, número de matrículas na educação básica, professores com ensino superior, despesas com educação, número de estabelecimentos de saúde, mortes entre zero e 
quatro anos, mortes por causas mal definidas, despesas com saúde, e investimentos na saúde.

Os dados complementares foram obtidos no portal da transparência e do balanço patrimonial da prefeitura do município de Santana do Livramento em relação aos gastos com saúde e educação, além de dados do Instituto Brasileiro de Geografia e Estatística (IBGE), Fundação de Economia e Estatística (FEE), Instituto de Pesquisa Econômica Aplicada (IPEDATA), Instituto Nacional de Estudos e Pesquisas Educacionais Anísio Teixeira (INEP), Departamento de Informática do Sistema Único de Saúde (DataSUS) e Observatório do PNE (Plano Nacional de Educação) em relação às áreas de emprego e renda, educação, saúde e dados demográficos.

As análises foram feitas a partir de estatística descritiva, buscando evidenciar características da evolução do desenvolvimento do município. Estas análises foram complementadas qualitativamente por entrevistas, realizadas durante o início do ano de 2018, com o secretário da Saúde em atividade, o qual exerceu também o cargo de secretário de Desenvolvimento Econômico do município em período anterior; com a atual secretária da Educação; com o ex-prefeito do município, que exerceu seu mandato no período de 2005 a 2012; e com o atual presidente da Associação Comercial e Industrial de Santana do Livramento (ACIL).

\section{A evolução do município}

O município de Santana do Livramento tem uma área de $6.950,4 \mathrm{~km}^{2}$ e possuía 80.256 habitantes no ano de 2017. Quanto aos indicadores sociais, possuía uma taxa de analfabetismo de 4,23\%, entre as pessoas com 15 anos ou mais, uma expectativa de vida ao nascer de 75,77 anos (dados de 2010) e um coeficiente de mortalidade infantil de 12,62 por mil nascidos vivos (dado de 2016) (FEEDADOS, 2018). O último dado para o IDH foi de 0,727, no ano 2010 (PNUD, 2019). Quanto aos indicadores econômicos, o PIB foi de R $\$ 2.303$ milhões no ano de 2016, o que gerou uma renda per capita aproximada de R\$28.900 para aquele ano (IBGE, 2019). O Índice de Gini de 2010 foi de 0,5542 e apresenta uma economia com concentração de renda (apesar deste ser menor que o índice do ano 2000, que foi de 0,6081) (DATASUS, 2019). Importante destacar que foi considerada, como já mencionado, uma região de economia estagnada pela metodologia definida pelo PNDR.

Segundo os dados do Firjan (Figura 1), observa-se que o IFDM do município de Santana do Livramento, em comparação com o IFDM do estado do Rio Grande do Sul, não demonstra significativa diferença de nível de desenvolvimento. Percebe-se que, de 2008 a 2016, os níveis de desenvolvimento estavam bem próximos da média, destacando-se os anos de 2009, 2010, 2015 e 2016 quando o IFDM municipal foi maior que a média do IFDM estadual. Observa-se que o município vem obtendo 
um desenvolvimento considerável em relação ao estado: ocorreu um crescimento médio de $1,74 \%$ ao ano, enquanto o RS obteve um crescimento de $1,12 \%$ ao ano.

Figura 1 - IFDM total, educação, saúde e emprego e renda, e PIB em milhão de R\$, Santana do Livramento, e IFDM total do RS, 2005 e 2016
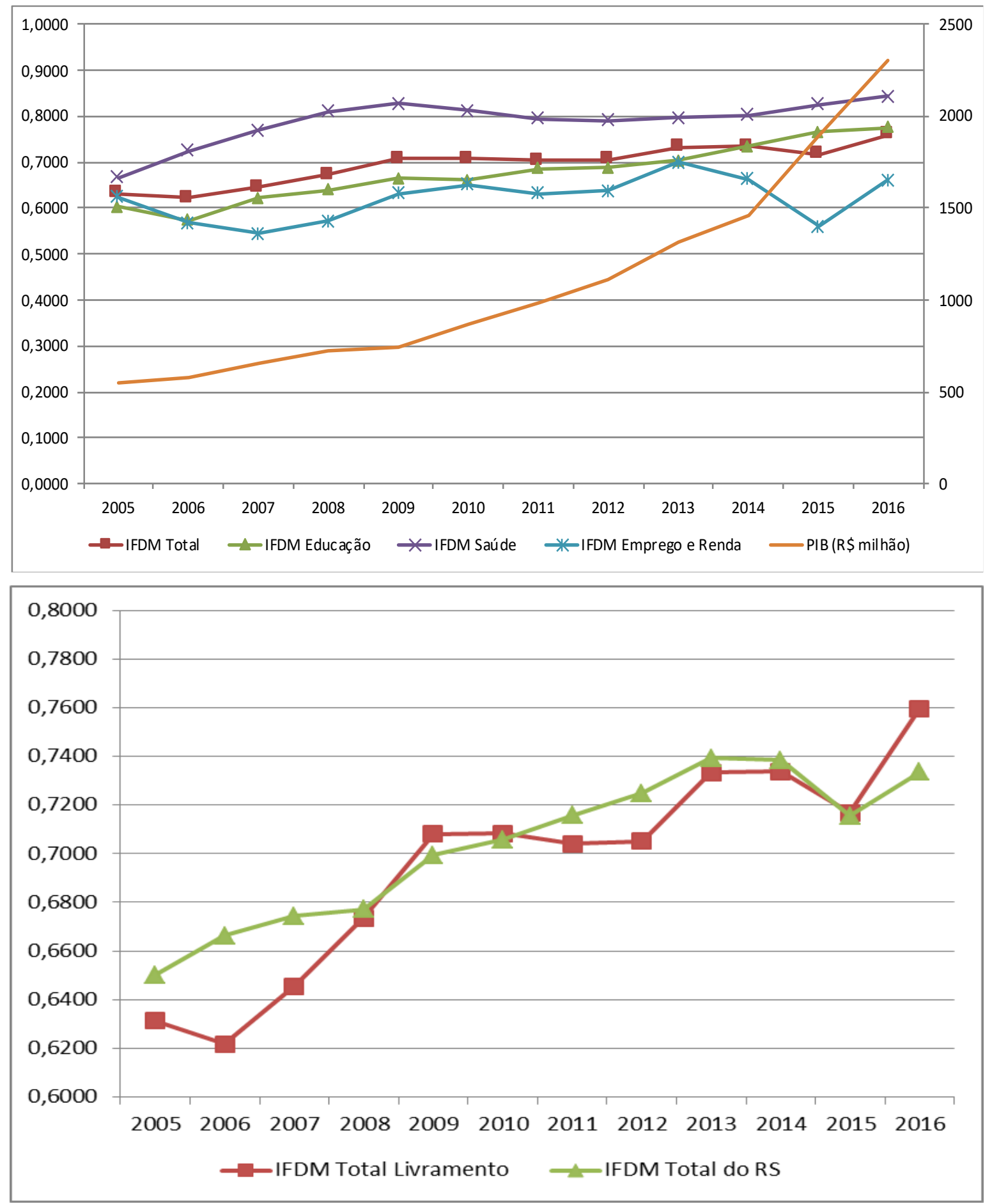

Fonte: Elaboração própria a partir dos dados de Firjan (2018) e IBGE (2018).

Nota: O PIB está a preços correntes com referência no ano de 2010. 
A Figura 1 permite observar ainda os dados do PIB do município no período de 2005 a 2016 (deflacionados para o ano de 2010 e apresentados em milhão de reais), evidenciado o crescimento econômico que o município teve durante esta série histórica. Observa-se um aumento constante do PIB no município para o período analisado. Este inicia a série no ano de 2005 com o valor de $\mathrm{R} \$ 546$ milhões de reais e termina no ano de 2015 com o valor de $\mathrm{R} \$ 2.303$ bilhões de reais, representando uma taxa média de crescimento de $14 \%$ ao ano e um aumento acumulado de $322 \%$ no período. Quando se observam os desdobramentos do IFDM (Saúde, Educação e Emprego e Renda) percebe-se um crescimento constante do IFDM Total que era 0,6312 em 2005 (próximo ao limite inferior do desenvolvimento moderado), chegando a 0,7597 em 2016 (ainda desenvolvimento moderado, mas com uma melhora de $20 \%$ ao longo da série). Pode-se dizer que a saúde e a educação contribuíram fortemente para este desempenho, enquanto o componente emprego e renda teve um desempenho menor que o dos demais.

Interessante destacar que o IFDM Saúde sempre teve o melhor desempenho, chegando a atingir o patamar de desenvolvimento alto a partir de 2014. Manteve, no período, taxas crescentes de 2005 a 2009 (de 0,6677 a 0,8271), recuando um pouco no período de 2009 a 2014 (de 0,8271 para 0,79), quando retomou a tendência de crescimento (de 0,79 para 0,8433). Ao todo aumentou $26 \%$ no período. $\mathrm{O}$ indicador FDM para educação manteve crescimento constante no período, avançando de crescimento moderado (no limite inferior) em $2015(0,6024)$ para desenvolvimento ainda moderado em 2016, mas com o indicador chegando a 0,7754 (um crescimento de quase $28 \%$ na série). No indicador IFDM emprego e renda houve oscilação significativa no período observado. Ocorreu uma retração entre 2005 e 2007 (de 0,6234 para 0,5446), cresceu para 0,6517 de 2007 a 2010, recuando um pouco nos dois anos seguintes, chegando a 0,7004 (melhor desempenho do período observado) em 2013. Após volta a recuar, fechando a série em 0,6603. Assim, no quesito emprego e renda, o município manteve-se, durante quase toda a série, dentro da faixa do desenvolvimento regular. O ano de 2013 foi exceção, quando o município chegou a apresentar desenvolvimento moderado para emprego e renda, mas o que não se sustentou nos anos seguintes.

As próximas subseções aprofundarão a análise sobre cada um dos componentes, tentando captar possíveis motivos para as flutuações observadas no período.

\section{Índice IFDM componente emprego e renda}

Como complemento de análise deste componente foram selecionadas informações sobre o número de empregos formais e os salários médios, fatores estes que influenciam no indicador IFDM, além de destacar características específicas da população, emprego e renda do município (Tabela 1).

Ao analisar-se a realidade do município, nota-se que tanto a estimativa da população total como a estimativa da população economicamente ativa (população entre $15 \mathrm{e}$ 
64 anos) têm, no período de 2006 a 2014, um declínio contínuo (diminui aproximadamente 4\% no acumulado do período). A população total chega a 2015 com 83.320 habitantes e a população economicamente é de 54.956 pessoas, o que equivale a aproximadamente $65 \%$ da população total em toda a série (FEEDADOS, 2018). De acordo com os dados do IBGE, o pessoal ocupado total aumentou durante a série, passando de 12.272 no ano de 2006, valor este correspondente a $21,45 \%$ do total de pessoas economicamente ativas, para 15.017 em 2015, correspondendo a $27,33 \%$. Vale ressaltar que o maior número de pessoas ocupadas ocorreu em 2013, com o número de 15.682, correspondendo a 28,69\% das pessoas economicamente ativas do município. Isso coincide com o ano de melhor desempenho do 'IFDM emprego e renda' observado na Figura 1. A média de crescimento do pessoal ocupado total foi de 2,31\% ao ano, enquanto a estimativa da população economicamente ativa diminuiu a uma média de $0,44 \%$ ao ano (como pode ser observado na Tabela 1).

Tabela 1 - População total, população economicamente ativa, pessoal ocupado, pessoal ocupado assalariado, remuneração média, número de empresas atuantes e PIB per capita, Santana do Livramento, 2005 a 2015

\begin{tabular}{cccccccc}
\hline Ano & $\begin{array}{c}\text { População } \\
\text { Total }\end{array}$ & $\begin{array}{c}\text { População } \\
\text { economicamente } \\
\text { ativa }\end{array}$ & $\begin{array}{c}\text { Pessoal } \\
\text { ocupado }\end{array}$ & $\begin{array}{c}\text { Pessoal } \\
\text { ocupado } \\
\text { assalariado }\end{array}$ & $\begin{array}{c}\text { Remuneração } \\
\text { média (em } \\
\text { SM) }\end{array}$ & $\begin{array}{c}\text { Número } \\
\text { empresas } \\
\text { atuantes }\end{array}$ & $\begin{array}{c}\text { PIB } \\
\text { papita }\end{array}$ \\
\hline 2005 & - & - & - & - & - & [nd] & [nd] \\
2006 & 89.074 & 57.207 & 12.272 & 8.688 & 2,1 & [nd] & 6.466 \\
2007 & 88.305 & 56.728 & 12.730 & 8.944 & 2 & [nd] & 7.406 \\
2008 & 87.460 & 56.351 & 13.101 & 9.263 & 2 & 2.809 & 8.312 \\
2009 & 86.690 & 55.962 & 13.537 & 9.649 & 1,9 & 2.959 & 8.616 \\
2010 & 85.716 & 55.422 & 14.305 & 10.185 & 1,9 & 3.209 & 10.591 \\
2011 & 84.774 & 55.087 & 14.600 & 10.764 & 1,9 & 2.836 & 12.011 \\
2012 & 83.769 & 54.697 & 14.662 & 10.929 & 1,9 & 2.773 & 13.738 \\
2013 & 83.494 & 54.653 & 15.682 & 11.942 & 1,9 & 2.891 & 15.768 \\
2014 & 83.115 & 54.519 & 15.184 & 11.948 & 2 & 2.542 & 17.510 \\
2015 & 83.320 & 54.956 & 15.017 & 11.655 & 2 & 2.541 & 22.915 \\
2016 & 80.600 & 53.162 & 15.395 & [nd] & 2 & 2.241 & 28.573 \\
\hline
\end{tabular}

Fonte: FEEDADOS (2018); IBGE (2019).

Nota: Os dados de população economicamente ativa e pessoal ocupado foram estimados para o ano de $2016 \mathrm{com}$ base nas proporções dos anos anteriores com relação à população total.

Para a série de pessoal ocupado assalariado, observa-se um aumento de 2006 a 2014. O primeiro ano com o total de 8.688 (correspondendo a $15,19 \%$ do total da estimativa da população economicamente ativa) e o ano de 2014 com o total de 
11.948 pessoas ocupadas assalariadas (representando $21,92 \%$ do total da estimativa da população economicamente ativa), observa-se uma queda somente no ano de 2015 representando 1\%. A queda de ambos pode ser explicada pela crise que iniciou em 2014 e que teve como uma de suas causas a recessão econômica do país. Observa-se que o salário médio mensal em número de salário-mínimo para o município variou durante o período analisado, destacando-se o ano de 2006 com o maior valor de 2,1 e os anos de 2009 a 2013 com o menor valor de 1,9 SM. Este valor médio de remuneração encontra-se em patamar semelhante ao do Estado do RS no mesmo período (FEEDADOS, 2019).

Outro dado importante a ser analisado nesta área é o número de empresas atuantes no município (Tabela 1). Segundo os dados do IBGE, observa-se uma oscilação para a série histórica de 2008 a 2015: 2010 destaca-se como o ano com o maior número de empresas atuantes, contando com 3.209 empresas e 2016 com o menor número, contando com 2.241 empresas atuantes, representando uma queda de $30 \%$ neste período.

Para a série histórica do PIB per capita do município, nos anos de 2006 a 2016, já deflacionados para o ano de 2010, observa-se também um aumento constante, iniciando a série com o valor de $\mathrm{R} \$ 6.466$ reais e terminando a série em 2016 com o valor de $\mathrm{R} \$ 28.573$ reais, 341\% maior que o primeiro número da série. $\mathrm{O}$ crescimento médio do PIB per capita no período foi de $16 \%$, o que pode ser explicado pelo crescimento do PIB (Figura 1), e que implicou na ampliação do pessoal ocupado e dos salários médio mensal (em pequenos percentuais e acompanhados de uma redução de empresas atuantes no ambiente formal da economia). Novamente coincide com o ano de melhor desempenho do IFDM Emprego e Renda. Em relação aos salários médios para o mesmo período, obtevese nos anos de 2010 a 2013 um valor constante de 1,9 salário médio mensal aumentando para 2 até o ano de 2015. Sendo estas duas variáveis que contribuíram para o crescimento do PIB per capita.

Outra variável que contribuiu para o aumento do PIB per capita foi a diminuição da população durante o período analisado, conforme pode ser observado na Tabela 1. No ano de 2006 a 2016 a população diminuiu de 89.074 para 80.600 habitantes, representando uma queda de quase $10 \%$ ao longo de 10 anos.

O aumento do IFDM para a série pode ser explicado em parte pelo aumento do número total de pessoas ocupadas, a uma média de $2,31 \%$ ao ano, enquanto no mesmo período o número de pessoas economicamente ativas baixou, em média, $0,44 \%$ ao ano. Outro fator que pode ter influenciado para o mesmo é a questão que o salário médio mensal em número de salário-mínimo manteve-se sem grande variação, a uma média de 1,96, enquanto o salário médio do estado e do país terminaram em queda.

Outra variável explicativa que poderia ser utilizada para mensurar a queda do índice seria a desigualdade. No entanto, a falta de dados secundários permite grande 
detalhamento, fazendo com que se tenha o Índice de Gini para o município apenas para os anos de 1991, 2000 e 2010. Analisando a pequena queda do salário médio e sua influência no índice IFDM supõe-se que a principal variável explicativa para a diminuição do IFDM, observada em alguns anos, poderia ser a redução da desigualdade, uma vez que o Índice Gini diminuiu 8,9\% entre $2000(0,6081)$ e 2010 $(0,5542)$.

Quando são trabalhadas as informações levantadas nas entrevistas, são evidenciadas diversas atividades como explicativas da dinâmica do indicador 'emprego e renda', as quais se destaca a seguir. A) O desenvolvimento da produção de uvas viníferas e o desenvolvimento de algumas vinícolas locais, as quais fazem o processo de industrialização do vinho na região; B) Desenvolvimento do parque eólico (ainda em instalação) trouxe movimentação econômica para a região, inclusive via instalação da sede administrativa da Eletrosul ainda em 2010. Tem-se expectativa que a entrada dos rendimentos deste setor no município altere de forma significativa a capacidade de geração e renda da região. C) Desenvolvimento da produção de soja na região, ao longo dos últimos 15 anos, com desenvolvimento de empresa especializada na assistência técnica, produção, armazenagem e comercialização dos grãos. D) Evolução paulatina do turismo regional, o qual inicia como turismo de compras, com os freeshops uruguaios, mas aos poucos se expande para outras formas, em especial, o turismo de eventos (enogastronomia) e receptivo (hotéis fazenda, turismo rural, estâncias termais). E) Incentivo ao empreendedorismo local, com especial cuidado com a emergência de agroindústrias locais. Um projeto articulado pela prefeitura municipal entre o ano de 2009 até 2012 repercutiu no cadastro e fortalecimento de 62 agroindústrias locais, permitindo o desenvolvimento de produção e comércio formal de produtos como linguiça, queijo e laticínios, carnes pré-preparadas (almôndegas, bifes empanados e carnes recheadas), entre outros, nos mercados do próprio município. Ainda neste esforço, destaca-se a formalização do comércio ambulante (camelôs), levando-os a tornarem-se microempreendedores. F) Emergência do complexo olivícola, o qual já tem produção local de azeite de oliva e vem se expandido de forma consistente ao longo dos últimos 10 anos. G) A chegada das universidades, que ao longo dos últimos 13 anos também contribuiu para mudanças na dinâmica econômica local, em especial no que tange ao comércio, alimentação e setor imobiliário.

As entrevistas ainda destacam que o município precisa avançar mais nas questões do comércio, indústria, prestação de serviços, agricultura e pecuária, bem como no atendimento de condições de infraestrutura para a expansão dos negócios existentes e o atendimento de novos negócios. As condições das estradas locais e do escoamento da produção, continuam sendo um grande entrave ao crescimento econômico da região. Melhorias neste sentido têm dependido de investimentos 
externos, como é o caso das soluções apresentadas por vitivinícolas e olivicultures para a movimentação de suas produções ${ }^{1}$.

Estes elementos podem realmente ter contribuído para a dinâmica observada nos indicadores até aqui apresentados.

\section{Índice IFDM componente Educação}

A Tabela 2 traz informações acerca o número de matrículas realizadas, número de docentes com ensino superior e as despesas que o município teve com a educação, fatores estes que influenciam no indicador IFDM Educação.

\section{Tabela 2 - Série histórica do número de matrículas realizadas na educação, de Santana do Livramento de 2005 a 2015}

\begin{tabular}{lcccc}
\hline Ano & $\begin{array}{c}\text { Matrículas } \\
\text { realizadas }\end{array}$ & $\begin{array}{c}\text { Professores com } \\
\text { ensino superior }\end{array}$ & $\begin{array}{c}\text { Professores com } \\
\text { ensino superior }(\%)\end{array}$ & $\begin{array}{c}\text { Despesas com } \\
\text { educação (R \$ 1.000) }\end{array}$ \\
\hline 2005 & 20.587 & {$[\mathrm{nd}]$} & {$[\mathrm{nd}]$} & [nd] \\
2006 & {$[\mathrm{nd}]$} & {$[\mathrm{nd}]$} & $7 \mathrm{nd}$ & [nd] \\
2007 & 19.602 & 710 & 78,0 & [nd] \\
2008 & {$[\mathrm{nd}]$} & 702 & 77,3 & [nd] \\
2009 & 18.403 & 686 & 75,9 & 17.413 \\
2010 & {$[\mathrm{nd}]$} & 681 & 78,0 & 23.431 \\
2011 & {$[\mathrm{nd}]$} & 703 & 76,1 & 26.069 \\
2012 & 16.736 & 736 & 78,1 & 27.838 \\
2013 & {$[\mathrm{nd}]$} & 755 & 77,4 & 27.610 \\
2014 & {$[\mathrm{nd}]$} & 757 & 73,3 & 32.529 \\
2015 & 15.617 & 755 & {$[\mathrm{nd}]$} & 35.990 \\
2016 & {$[\mathrm{nd}]$} & & 42.113 \\
\hline
\end{tabular}

Fonte: Elaboração própria a partir de IBGE (2018), MEC (2018) e PMSL (2018).

Segundo os dados do IBGE pode-se analisar na série histórica uma diminuição constante no número das matrículas. $\mathrm{O}$ ano de 2005 inicia com 20.857 matrículas na rede educacional, tanto privada como pública, e termina o ano de $2015 \mathrm{com}$ 15.617 matrículas. Essa queda no número das matrículas pode ser atribuída ao

\footnotetext{
${ }^{1}$ A fala do ex-prefeito Wainer Machado ajuda na construção desta afirmativa: "um fator negativo para o desenvolvimento local relaciona-se com a infraestrutura, principalmente de estradas. O governo municipal deve ser responsável por alavancar o desenvolvimento municipal. No entanto, não consegue fazer isso sozinho, precisa haver um trabalho em conjunto com os investidores. Porém, isso não ocorre com os investidores locais, os quais não buscam a mudança, mantendo seu investimento e produção voltados para a pecuária. Grande parte dos investimentos que vem sendo feitos dependem de investidores externos ao município, como no caso da Salton e de algumas empresas olivícolas".
} 
envelhecimento da população, redução da taxa de nascidos e redução geral da população em 10\% ao longo de 10 anos (consequência destas duas questões, associadas à migração de população para outras regiões de economia mais dinâmica).

De acordo com os dados do IBGE (2019), o número de nascidos vivos reduziu ao longo dos anos observados. Em 2005 era de 1.435 nascidos vivos no município. Este número reduziu-se para 1.150 no ano de 2016. A redução é constante entre 2005 a 2010, cresce de 2010 a 2015 (sem, no entanto, voltar aos patamares do início da série), voltando a cair em 2016.

Sobre o envelhecimento, a faixa etária de zero a quatro anos reduziu em $27,28 \%$ do ano de 2005 para o ano de 2015. A faixa etária de cinco a nove anos de idade também reduziu a uma taxa de $32,53 \%$ neste período. Esta redução da população se mantém até a faixa de 45 a 49 anos, com exceção da faixa dos 16 a 19 anos, que obteve um aumento na sua participação de 3,14\%. A partir da faixa etária dos 50 a 54 anos até 80 anos ou mais há um aumento na participação da população, a uma taxa média de 21,30\% (FEEDADOS, 2018).

Analisando os números relacionados aos docentes, observa-se entre 2013 e 2016 se um aumento constante no número absoluto de docentes, sendo estes os anos com maior número de professores atuando. No entanto, nota-se que a taxa de docentes com ensino superior diminuiu ao longo da série. Neste contexto, o ano de 2016 é o de menor taxa de docentes com ensino superior, com 69,8\%. Em 2008 e 2011, 78\% dos professores em atuação tinham ensino superior. Esta redução relativa pode ter ocorrido por conta da ampliação de vagas nos primeiros anos de formação, onde o ensino superior não é exigido.

Analisando os dados disponíveis na série histórica dos anos de 2009 a 2016, sobre as despesas com educação, deflacionados pelo Índice Nacional de Preços do Consumidor Amplo (IPC-A), nota-se um aumento nas despesas com a educação no município. O ano com o maior valor de despesa foi 2016 com o valor de $\mathrm{R} \$ 42,113$ milhões de reais, representando uma taxa média de crescimento de $11,51 \%$ ao ano. Durante a série houve um crescimento contínuo das despesas, exceto no ano de 2013, em que houve queda em relação ao ano anterior no valor de $\mathrm{R} \$ 27,610$ milhões de reais, representando uma taxa de $0,82 \%$. Para se obter os valores das despesas com a educação foram incluídos gastos com salários e benefícios dos servidores, contratações de serviços, materiais de consumo e investimentos. Despesas estas que expressam os gastos para manter, fomentar e aprimorar a educação no município.

$\mathrm{Na}$ análise qualitativa, a presença das universidades, cursos técnicos e os polos de ensino à distância no município são identificados como fatores determinantes para a melhoria da qualidade de ensino. Isso fica evidenciado na fala da Secretária da Educação no ano de 2018, Maria Goreti. Para ela, a chegada das universidades, cursos técnicos e os polos de ensino a distância permitiram que grande parte dos 
jovens tivesse acesso a uma educação com qualidade, modificando seu empenho durante os anos de formação na educação básica. Observa-se no período recente uma queda considerável na evasão escolar no município, o que também ajuda na melhoria do índice. Estes podem ser associados direta e indiretamente às políticas públicas federais e estaduais voltadas para a educação, as quais contribuíram para disponibilidade de recursos e desenvolvimento de aspectos de gestão do ensino em seus vários níveis.

São indicados como determinantes das variações negativas nos indicadores observados: A) a educação infantil, que hoje encontra-se aos cuidados do município, é uma área de difícil gerenciamento pela dificuldade de se ofertar vagas suficientes para atender as crianças de zero a três anos, o que faz com que o município ainda não tenha alcançado $100 \%$ das crianças nesta faixa etária atendidas; e B) o município, por questões de orçamento, não tem feito concurso para professores, o que acaba ocasionando um ambiente instável de contratos, tornando o ensino, muitas vezes, descontinuado. Apesar do crescimento que o IFDM mostrou durante o período, ele se manteve como desenvolvimento moderado.

\section{IFDM componente saúde}

A partir dos dados do DataSUS (2018) nota-se um aumento crescente no número dos estabelecimentos de saúde no município (Tabela 3). Para este valor foram considerados os centros de saúde e unidades básicas de saúde; clínicas e ambulatórios especializados; consultórios; farmácias; laboratórios; policlínicas; pronto socorro; hospitais; secretaria de saúde e as unidades móveis de urgências e emergências. No fim do período analisado observa-se que houve um aumento de 62 estabelecimentos em relação ao início da série, quase dobrando os iniciais 76 estabelecimentos do ano de 2006. Esses números podem representar, quantitativamente, que o atendimento a população na área da saúde aumentou durante o período.

Em relação à mortalidade infantil de zero a quatro anos e a mortalidade de causas mal definidas, percebe-se que ocorreu uma diminuição constante da mortalidade infantil. Em 2005 ocorreram com 29 mortes, destacando-se o ano de 2015 com apenas 11 mortes (o menor número da série), mas terminando a série com 18 mortes em 2016. Segundo os dados de mortes por causas mal definidas, observa-se também uma oscilação durante o período analisado, com destaque para o ano de 2005 com o maior número de mortes, 50, e em 2008 com o menor número, 18 falecimentos. Analisando-se todo o período, a oscilação ocorre no entorno da média de 41 mortes ao ano, por causas mal definidas (Tabela 3). 
Tabela 3 - Série histórica do número de estabelecimentos de saúde, mortes de zero a quatro anos, mortes por causas mal definidas, despesas com a saúde e investimentos em saúde, Santana do Livramento, 2006 a 2017

\begin{tabular}{cccccc}
\hline Ano & $\begin{array}{c}\text { Estabelecimentos } \\
\text { de saúde }\end{array}$ & $\begin{array}{c}\text { Mortes de } 0 \mathrm{a} 4 \\
\text { anos }\end{array}$ & $\begin{array}{c}\text { Mortes por } \\
\text { causas mal } \\
\text { definidas }\end{array}$ & $\begin{array}{c}\text { Despesas com } \\
\text { saúde }(\mathrm{R} \$ \\
1.000)\end{array}$ & $\begin{array}{c}\text { Investimentos } \\
\text { em saúde }(\mathrm{R} \$ \\
1.000)\end{array}$ \\
\hline 2005 & {$[\mathrm{nd}]$} & 29 & 50 & {$[\mathrm{nd}]$} & {$[\mathrm{nd}]$} \\
2006 & 76 & 26 & 32 & {$[\mathrm{nd}]$} & {$[\mathrm{nd}]$} \\
2007 & 90 & 17 & 28 & {$[\mathrm{nd}]$} & {$[\mathrm{nd}]$} \\
2008 & 91 & 16 & 18 & {$[\mathrm{nd}]$} & [nd] \\
2009 & 92 & 12 & 22 & 18.782 & 368 \\
2010 & 109 & 24 & 33 & 23.644 & 868 \\
2011 & 115 & 18 & 24 & 23.523 & 1.520 \\
2012 & 118 & 15 & 47 & 25.297 & 1.096 \\
2013 & 120 & 18 & 55 & 23.422 & 1.372 \\
2014 & 130 & 13 & 31 & 28.932 & 1.925 \\
2015 & 133 & 11 & 43 & 25.997 & 302 \\
2016 & 138 & 18 & 40 & 35.845 & 583 \\
\hline
\end{tabular}

Fonte: Elaboração própria a partir dos dados de DataSUS (2018) e PMSL (2018).

Para contabilizar as despesas com a saúde foram considerados gastos com salários e benefícios dos servidores, sentenças judiciais, obrigações tributárias e contributivas, materiais de consumo e serviço, indenizações e restituições, contratações e os investimentos. Foram considerados os dados do portal da transparência do município, deflacionados pelo Índice Nacional de Preços do Consumidor Amplo (IPC-A). Para o ano de 2016, observa-se durante o período analisado uma oscilação nas despesas no entorno de $\mathrm{R} \$ 25.680$ milhões até o fim da série. $\mathrm{O}$ ano de 2016 se destaca expressivamente durante toda a série, pois foi o ano com maior valor de despesas com $\mathrm{R} \$ 35.845$ milhões e o ano de 2009 com o menor valor de despesas com $\mathrm{R} \$ 18.782$ milhões.

Em relação aos investimentos na área da saúde do município, pode-se perceber que houve também uma grande oscilação durante a série. Destaca-se o ano de $2011 \mathrm{com}$ $\mathrm{R} \$ 1,5$ milhão e 2014 com $\mathrm{R} \$ 1,9$ milhão, sendo estes os anos com maiores investimentos na saúde. Já os anos de 2009 com $R$ \$ 367 mil reais e 2015 com R \$ 302 mil reais investidos, foram os anos de menor investimento. A série termina no ano de $2016 \mathrm{com}$ um valor baixo de investimento comparado aos anos anteriores, com o valor de $\mathrm{R} \$ 583$ mil reais.

Partindo para análise qualitativa, as entrevistas indicam a crise do Hospital Público Santa Casa de Misericórdia, o qual passou por problemas financeiros, ficando em vias de fechar, como uma das explicações para as variações negativas observadas no índice (o secretário da Saúde no ano de 2018, Sergio Aragon, ratifica esta afirmativa). 
Também em período recente foi feita uma reestruturação da rede básica de atendimento à população, passando por dificuldades e modificações. Por outro lado, as melhorias observadas no indicador podem ser atribuídas à implantação das Estratégias de Saúde à Família (ESF) e as Unidades Básicas de Saúde (UBS), proporcionaram um atendimento mais descentralizado para a população ampliando o alcance da saúde a mais pessoas e personificando o atendimento. Além destas, foram destacadas as políticas públicas focadas na questão da diminuição da mortalidade infantil, as quais explicam a melhora do índice observado anteriormente (a entrevista com Wainer Machado e com Sergio Aragon ajudam a ratificar esta afirmativa).

\section{Considerações finais}

O objetivo geral deste artigo foi analisar o desenvolvimento socioeconômico no município entre o período de 2005 a 2016, considerando-se o Índice Firjan de Desenvolvimento Municipal (IFDM), complementado por outros indicadores econômicos e sociais. De modo geral, pode-se dizer que o município apresentou avanços no seu desenvolvimento socioeconômico, no período analisado, com destaque para a educação e para a saúde. Os dados mostraram que este é um município de desenvolvimento moderado, estando de acordo com os dados explicativos utilizados para a análise do período estudado.

Diante do exposto, pode-se dizer que o município vem se desenvolvendo durante os anos em cada uma das áreas, destacando-se na saúde como a mais desenvolvida pelo seu IFDM e chamando a atenção para a área do emprego e renda, sendo o componente com os menores índices. Importante destacar que os melhores desempenhos foram observados nos setores onde existem políticas públicas de âmbitos estadual e federal. No entanto, no ambiente de emprego e renda, que depende de iniciativas privadas, para além dos incentivos públicos, apesar de observar-se um crescimento significativo do PIB e do PIB per capita municipal, percebe-se uma dinâmica mais frágil de desenvolvimento, com piores desempenhos nos indicadores IFDM.

Expectativas positivas podem ser criadas a partir da emergência de novos setores produtivos, como a vitivinicultura, olivicultura, a produção de leite e laticínios, o desenvolvimento da agricultura familiar e a produção de orgânicos, o desenvolvimento do parque eólico e o desenvolvimento do turismo receptivo. $A$ priori, a evolução destes setores pode mudar a dinâmica de emprego e renda do município, atuando sobre questões que são percebidas como falhas no IFDM emprego e renda. Também podem melhorar o desenvolvimento econômico regional, por gerarem potenciais efeitos de encadeamento com outros setores produtivos já existentes no município. Os efeitos de longo prazo, oriundos da 
presença de universidades no município, também podem contribuir para o desenvolvimento de Santana do Livramento (em especial o humano).

Sendo um processo e tendo evolução dinâmica, o acompanhamento constante dos indicadores de desenvolvimento, bem como da realidade que os alimenta, é necessário e salutar para orientar o desenvolvimento do município.

\section{Referências}

ALVES, J. A. A cúpula mundial sobre o desenvolvimento social e os paradoxos de Copenhague. Revista Brasileira de Política Internacional, vol. 40, n. 1, p. 142166, 1997.

AMARO, Rogério Roque. Desenvolvimento - um conceito ultrapassado ou em renovação? Da teoria à prática e da prática à teoria. Cadernos de Estudos Africanos, n. 4, p. 35-70, 2003.

AREND, Marcelo; CARIO, Silvio Antônio Ferraz. Desenvolvimento e desequilíbrio industrial no Rio Grande do Sul: uma análise secular evolucionária. Economia e Sociedade, vol. 19, n. 2, p. 381-420, 2010.

BRASIL. Indicadores de desenvolvimento brasileiro. Assessoria Econômica do Ministério do Planejamento, Orçamento e Gestão. vol. 27, 2013.

BRESSER-PEREIRA, Luiz Carlos. O conceito histórico de desenvolvimento econômico (= Texto para discussão EESP, v. 157). Rio de Janeiro: FGV, 2006.

CAGGIANI, Ivo. Sant'Ana do Livramento: 150 anos de história. Sant'Ana do Livramento: Associação Santanense Pró-Ensino Superior, 1983.

CAGGIANI, Ivo. 100 Anos de Comércio. Sant'Ana do Livramento: EDIGRAF, 1991.

CARDOSO, Fernando Henrique. Desenvolvimento: o mais político dos temas econômicos. Revista de Economia Política, vol. 15, n. 4, p. 148-155, 1995.

DATASUS - Departamento de Informática do SUS. Tabelas nacionais do SUS. Disponível em: http://tabnet.datasus.gov.br/cgi/ibge/censo/cnv/ginibr.def. Acesso em: set. 2018. 
DATASUS - Departamento de Informática do SUS. Tabelas nacionais do SUS. Disponível em: http://tabnet.datasus.gov.br/cgi/ibge/censo/cnv/ginibr.def. Acesso em: jun. 2019.

DOWBOR, L. Gestão social e transformação da sociedade. In: ARBIX, G; ZILBOVICIUS, M.; ABRAMOVAY, R. (Org.) Razões e ficções do desenvolvimento. São Paulo: EDUSP, 2001.

FAVERO, Marcos; DUARTE, Gabriel. Continuidade e limites: urbanismos na fronteira Brasil-Uruguai. São Paulo, 2014. Disponível em: http:/ / www.anparq.org.br/dvd-enanparq-3/htm/Artigos/SC/ORAL/SC-CDR083_FAVERO_DUARTE.pdf. Acesso em: 10 set. 2017.

FEEDADOS - Banco de Dados Dinâmico da FEE. Feedados. Disponível em: http:// feedados.fee.tche.br/feedados. Acesso em: out. 2018.

FIRJAN. Índice FIRJAN de desenvolvimento municipal. Rio de Janeiro: Federação das Indústrias do Estado do Rio de Janeiro. Disponível em: http://www.firjan.org.br. Acesso em: 27 out. 2017.

FIRJAN. Índice FIRJAN de desenvolvimento municipal. Rio de Janeiro: Federação das Indústrias do Estado do Rio de Janeiro. Disponível em: http://www.firjan.org.br. Acesso em: fev. 2019.

IBGE. Sistema IBGE de Recuperação Automática - SIDRA. Rio de Janeiro: Instituto Brasileiro de Geografia e Estatística. Disponível em: https://sidra.ibge.gov.br. Acesso em: out. 2018.

IBGE. Sistema IBGE de Recuperação Automática - SIDRA. Rio de Janeiro: Instituto Brasileiro de Geografia e Estatística. Disponível em: https://sidra.ibge.gov.br. Acesso em: jun. 2019.

IBGE. IBGE Cidades. Rio de Janeiro: Instituto Brasileiro de Geografia e Estatística. Disponível em: https://cidades.ibge.gov.br. Acesso em: 7 set. 2020.

IPEA. O índice de desenvolvimento humano municipal brasileiro 2014. Brasília: Instituto de Pesquisa Econômica Aplicada. Disponível em: http://www.ipea.gov.br/ agencia/images/stories/PDFs/livros/livros/141125_atlas_introducao. Acesso em: 29 out. 2017.

IPEA. Ipeadata. Brasília: Instituto de Pesquisa Econômica Aplicada. Disponível em: http://www.ipeadata.gov.br/Default.aspx. Acesso em: out. 2018. 
KLIKSBERG, Bernardo. Repensando o Estado para o desenvolvimento social: superando dogmas e convencionalismos. São Paulo: Cortez, 1998.

LAMPREIA, Luiz Felipe. Relatório brasileiro sobre desenvolvimento social. Estudos Avançados, vol. 9, n. 24, p. 9-74, 1995.

MALUF, R. S. Atribuindo sentido(s) à noção de desenvolvimento econômico. Estudos Sociedade e Agricultura, p. 53-86, 2000.

MEC. Plano nacional de educação - PNE. Brasília: Ministério da Educação. Disponível em: http://pne.mec.gov.br. Acesso em: set. 2018.

MELO, Chanaísa. Fragmentos da memória de uma fábrica na Coleção Fotográfica Laneira Brasileira Sociedade Anônima. 2013. 133f. Dissertação (Mestrado em Memória Social e Patrimônio Cultural) - UFPEL, Pelotas, 2013.

MIN. Política nacional de desenvolvimento regional. Brasília: Ministério da Integração Nacional, 2011. Disponível em: http://www.integracao.gov.br/ desenvolvimentoregional/index.asp. Acesso em: 18 jun. 2018.

MONTEBLANCO, Felipe Leindecker. O Espaço rural em questão: formação e dinâmica da grande propriedade e dos assentamentos da reforma agrária em Santana do Livramento/RS. 2013. 252f. Dissertação (Mestrado) - Programa de Pós-Graduação em Geografia, UFRGS, Porto Alegre, 2013.

NIEDERLE, Paulo André; RADOMSKY, Guilherme Francisco Waterloo. Introdução às teorias do desenvolvimento. PLAGEDER, 2016. Disponível em: http://www.ufrgs.br/cursopgdr/downloadsSerie/derad101.pdf. Acesso em: 10 jun. 2018.

OLIVEIRA, Jane Souto de. O traço da desigualdade social no Brasil. Rio de Janeiro: SPOC/IBGE, 1993. Disponível em: https://biblioteca.ibge.gov.br/ visualizacao/monografias/GEBIS\%20-\%20RJ/85-240-0473-8.pdf. Acesso em: 4 set. 2017.

OLIVEIRA, Gilson Batista de. Uma discussão sobre o conceito de desenvolvimento. Revista da FAE, vol. 5, n. 2, p. 37-48, 2002.

PMSL - Prefeitura Municipal de Santana do Livramento. Portal da transparência do município. Disponível em: http://transparencia.sdolivramento.com.br. Acesso em: out. 2018. 
PNUD. Atlas do desenvolvimento humano no Brasil. Disponível em: http://www.atlasbrasil.org.br/2013/pt/consulta. Acesso em: 18 jun. 2019.

SÁNCHEZ, Andrea Quadrelli. A fronteira inevitável: um estudo sobre as cidades de fronteira de Rivera (Uruguai) e Santana do Livramento (Brasil) a partir de uma perspectiva antropológica. 2002. 209f. Tese (Doutorado) - Programa de Pós-Graduação em Antropologia Social/ UFRGS, Porto Alegre, 2002.

SANTOS, Elinaldo L.; BRAGA, Vitor; SANTOS, Reginaldo S.; BRAGA, Alexandra M. S. Desenvolvimento: um conceito em construção.

Desenvolvimento Regional em Debate, vol. 2, n. 1, p. 44-61, 2012.

SCHÄFFER, N. O. Urbanização na fronteira: a expansão de Sant'Ana do Livramento/RS. Porto Alegre: Ed. UFRGS, 1993.

SILVA, Virgílio Afonso da. Direitos fundamentais. Disponível em: http://www3.usf.edu.br/galeria/getImage/252/6892347672477816.pdf. Acesso em: 19 maio 2018.

SEN, Amartya. Desenvolvimento como liberdade. São Paulo: Companhia das Letras, 2000.

SIEDENBERG, Dieter R. Indicadores de desenvolvimento socioeconômico: uma síntese. Desenvolvimento em Questão, vol. 1, n. 1, p. 45-71, 2011.

SOUZA, Nali de Jesus de. Desenvolvimento econômico. 1994. 
Data de submissão: 11/07/2019

Data de aprovação: 10/09/2020

Revisão: Daniela Matthes (português), Anderson de Miranda Gomes (inglês) e Yanet María Reimondo Barrios (espanhol).

Amanda da Maia Alves

Prefeitura Municipal de Santana do Livramento

Rua Waldomiro Bassedas, 807 - Bairro São Paulo

97575-478 Santana do Livramento/RS, Brasil

Orcid: https://orcid.org/0000-0002-6840-1789

E-mail: amandaalves.adma@gmail.com

Debora Nayar Hoff

Universidade Federal do Pampa (Campus Santana do Livramento)

Rua Barão do Triunfo, 1048 - Centro

97573-634 Santana do Livramento/RS, Brasil

Orcid: https://orcid.org/0000-0003-3528-1378

E-mail: deborahoff@gmail.com 
Amanda da Maia Alves e Debora Nayar Hoff 